\title{
Multi-scale analysis of rural housing land transition under China's rapid urbanization: The case of Bohai Rim
}

\author{
Tingting Li ${ }^{\text {a, b }}$, Hualou Long ${ }^{\text {a, *, Yongqiang Liu }}{ }^{\text {a, b }}$, Shuangshuang $\mathrm{Tu}^{\mathrm{a}, \mathrm{b}}$ \\ a Institute of Geographic Sciences and Natural Resources Research, Chinese Academy of Sciences, Beijing 100101, China \\ ${ }^{\mathrm{b}}$ University of Chinese Academy of Sciences, Beijing 100049, China
}

\section{A R T I C L E I N F O}

\section{Article history:}

Received 26 March 2015

Received in revised form

20 April 2015

Accepted 21 April 2015

\section{Keywords:}

Land use transition

Driving forces and mechanism

New-type urbanization

Rural housing land consolidation

Spatial econometric regression model

\begin{abstract}
A B S T R A C T
With the rural-to-urban migration under China's rapid urbanization, the Bohai Rim of China experienced dramatic rural housing land transition (RHLT) in the last decade, especially in terms of per capita rural housing land (PRHL). The objectives of this study are to (i) analyze the spatio-temporal patterns of RHLT, and (ii) detect the underlying driving forces and mechanism of RHLT in Bohai Rim during 2000-2010. To achieve these goals, we collected and rasterized high resolution Landsat TM data, socio-economic and physical environmental data for the Bohai Rim. Spatial econometric regression models at both grid scale and county scale were developed to examine the driving forces of RHLT in Bohai Rim. The results indicated that the distribution of rural housing land was characterized by vertical zonality, i.e., the proportion of rural housing land decreased gradually with the increase of elevation, and was more sensitive to slope than to elevation. The results of hot spots analysis showed that the spatial mismatch of rural housing land change and rural population migration made the regional differences of RHLT more remarkable, based on which four rural housing land consolidation regional types were differentiated. The authors argue that towns are effective hubs for linking the urban system and rural system, and it is better to get the farmers to migrate to towns instead of big cities in the process of pushing forward China's newtype urbanization in the future. For this, it is necessary to further improve related system and institution. Only by this way can the relationship between out-migrated farmers and rural housing land be orderly and completely removed, so as to smoothly pushing forward rural housing land consolidation.
\end{abstract}

(c) 2015 Elsevier Ltd. All rights reserved.

\section{Introduction}

Rural China has experienced a rapid and far-reaching transition in the past three decades since Deng Xiaoping launched economic reform in 1978 (Long, Li, Liu, Woods, \& Zou, 2012). With the rapid industrialization and urbanization, the rural population have been confronting with significant changes in demographic structures, employment opportunities, community organization, lifestyles and standard of living, accessibility and rural culture (Goodman, 2008; Long et al., 2012; Long, Li, Miao, Liu, Li, \& Meng, 2014; Mukherjee \& Zhang, 2007; Tilt, 2008; Unger, 2002; Zhang, Rozelle, \& Huang, 2001 ). These changes, especially the family structure miniaturization and improved living standards, raised the demand of rural housing land (Li, Liu, Long, \& Cui, 2014; Long, Heilig, Li, \& Zhang, 2007). In the absence of long-term planning and land use control,

\footnotetext{
* Corresponding author.

E-mail address: longhl@igsnrr.ac.cn (H. Long).
}

these changes led to the sprawl of rural housing land (Liu, Fang, \& Li, 2014; Deng, Wang, Hong, \& Qi, 2009; Long \& Li, 2012). During 2000-2008, China's rural resident population decreased from 808.37 million in 2000 to 721.35 million in 2008 , with a decrease of 87.02 million and by $10.8 \%$; however, rural housing land expanded from 16.53 million ha in 2000 to 16.66 million ha in 2008, with an increase of 0.13 million ha and by $0.8 \%$ (MLRC, 2009; NBSC, 2009).

The research of land use transitions has been a hot topic since the turn of the new millennium (Mather, 2004, 2007; Mather \& Fairbairn, 2000; Turner, Lambin, \& Reenberg, 2007; Carmona \& Nahuelhual, 2012; Mizutani, 2012; Ferreira, Alves, \& Shimabukuro, 2015; Romo-Leon, van Leeuwen, \& Castellanos-Villegas, 2014; Long et al., 2007, Long, Liu, Hou, Li, \& Li, 2014; Lambin \& Meyfroidt, 2010; Su, Jiang, Zhang, \& Zhang, 2011, Su, Xiao, Jiang, \& Zhang, 2012; Li \& Zhao, 2011; Long, 2014a). With the introduction of land use transitions to the academic circle of China (Long, 2003; Long \& Li, 2002), related researches combining with the characteristics of China's socio-economic development have been carried out extensively (Gong, Chen, Liu, \& Wang, 2014; Long et al., 2007, Long, Liu, 
et al., 2014; Su, Wang, Luo, Mai, \& Pu, 2014, Su, Yang, Hu, Luo, \& Wang, 2014). Recently, issues related to rural housing land transition in China have attracted interest among a wide variety of researchers, ranging from those who favor theoretical hypothesis and verification (Long et al., 2007), morphology evolution of rural settlements (Fang \& Liu, 2014), hollowed villages (Chen, Sun, \& Liu, 2010; Liu, Liu, Chen, \& Long, 2010; Long et al., 2012), rural housing land consolidation (Li et al., 2014; Long, 2014b), functional transition of the rural settlements (Zhu, Zhang, Li, \& Zhu, 2014), urban village (Liu, He, Wu, \& Webster, 2010; Liu, van Oort, Geertman, \& Lin, 2014; Lin \& De Meulder, 2012; Song, Zenou, \& Ding, 2008), to those who try to understand the spatio-temporal patterns, driving forces and coupling mechanism of rural housing land transition (Chen, Ye, Cai, Xing, \& Chen, 2014; Liu, Liu, Kong, Li, \& Tan, 2015; Long \& Li, 2012; Song \& Liu, 2014; Tan \& Li, 2013).

Since there exists obvious human-land conflicts (Liu, Fang, et al., 2014), the researches on rural housing land in China just focusing on land itself are incomplete, to some extent, and the "rural population-rural housing" joint research framework need to be paid more attentions. Compared with the increasing rural housing land, the rural population decreased with the key trends including mass migration from rural to urban areas and the development of 'villages-in -city'(chengzhongcun) of rural migrant workers (Chan, 2010; Liang, Chen, \& Gu, 2002; Chen et al., 2014; Song et al., 2008; Long et al., 2012). During 2000-2008, the per capita rural housing land (PRHL) of China expanded from $204.5 \mathrm{~m}^{2}$ to $231.0 \mathrm{~m}^{2}$ with an annual growth rate of $1.6 \%$, which was far greater than $0.1 \%$ that of rural housing land (MLRC, 2009; NBSC, 2009). This "population decrease but rural housing land increase" phenomenon resulted in the formation of hollowed villages (Liu, Liu, et al. 2010; Li, Liu, \& Long, 2010; Long et al., 2012).

Based on the understanding of land use transitions (Long \& Li, 2012), there are two categories of rural housing land transition (RHLT). One is the changes of dominant morphology of rural housing land, which means the quantity, structure and spatial pattern of rural housing land; another is the changes of recessive morphology, which includes the quality, property rights and management mode of rural housing land (Long \& Li, 2012). The change of PRHL belongs to the change of the recessive morphology (i.e., property rights) of rural housing land, which is one of the important components of rural housing land transition under rapid urbanization. However, the research of this kind of rural housing land transition has received much less attention. Currently, the analysis of the relationship between rural housing land and rural population changes mostly concentrated in the provincial scale constrained by data availability and its processing technology (Li et al., 2010; Song \& Liu, 2014). It is imaginable that the research outcomes based on the data at provincial scale are not competent to guide the practice of rural housing land consolidation at township or village level. The aims of this paper are: (1) to analyze the spatiotemporal pattern of RHLT especially in the aspect of PRHL based on $1 \mathrm{~km}$ grid data; (2) to detect the physical and socio-economic driving forces of RHLT with the aid of spatial econometric regression model at both grid scale and county scale in Bohai Rim using high-resolution Landsat TM data in 2000 and 2010, socio-economic data and physical environment data; and (3) to discuss some of the major implications for carrying out rural housing land consolidation and pushing forward China's new-type urbanization.

\section{Materials and methods}

\subsection{Study area}

This paper selects the Bohai Rim (including Beijing, Tianjin, Hebei, Liaoning and Shandong five provinces) as study area (Fig. 1).
It covers about 52.20 million ha, which accounts for $5.5 \%$ of the national land area. The north temperature monsoon climate dominates this region year round, with average annual temperature of $9.5{ }^{\circ} \mathrm{C}$, average annual rainfall of $590.6 \mathrm{~mm}$, all of which are beneficial for agricultural production. Therefore, the Bohai Rim is also an important agricultural base with arable land area of 2.7 million ha, which accounts for a quarter of the total arable land in China and produces $23 \%$ of national grain outputs.

As one of the economic growth poles of China, the Bohai Rim had undergone rapid urbanization during 2000-2010. The urbanization rate of Bohai Rim has increased from 39.5\% in 2000 to $54.9 \%$ in 2010 , which were higher than $36.2 \%$ and $50.0 \%$ of national level which is in 2000 and 2010, respectively. Its per capita GDP increased from 10,332 yuan in 2000 to 54,506 yuan in 2010 . Recently, the Bohai Rim was considered as China's "third engine" of economic growth, besides the Yangtze River Delta (which has Shanghai as the central city) and the Pearl River Delta (which has Guangzhou as the central city) (Yang, Liu, Long, \& Qiao, 2015).

Accompanied with the rapid urbanization, the elements of agricultural production achieved a rapid nonagricultural transition with the phenomenon of nonagricultural employment of rural population and expansion of rural construction land (Guo, Wang, Qiu, Wang, \& Liu, 2009). Under this circumstance, the PRHL changed dramatically and brought about rapid rural housing land transition. Meanwhile, the developed land amounted to $84 \%$ of total study area, which indicated that the reserved land resources were very scarce since most of the undeveloped land belonged to ecological land (Liu, Liu, \& Guo, 2011). The contradiction between the limit of land resources and the increasing need of construction land due to rapid socio-economic development was increasingly intensified; however, which can be released by carrying out rural housing land consolidation (Long et al., 2012). As such, the Bohai Rim is one of the typical areas to carry out the research on rural housing land transition under rapid urbanization.

\subsection{Data source}

The rural housing land data was obtained through detection analysis of historical Landsat TM (Thematic Mapper) satellite images in 2000 and 2010 from China National Environmental Monitoring Center. The $1 \times 1 \mathrm{~km}$ gridded demographic data was provided by the Data Sharing Infrastructure of Earth System Science (www.geodata.cn). The socio-economic data of 2000 and 2010 were mainly derived from "China statistical yearbook for regional economy", "China county statistical yearbook", "Tabulation on the 2000 population census of China" and "Tabulation on the 2010 population census of China". The missing data was supplemented from the Statistical Yearbook and the rural survey data of the five provinces in Bohai Rim. The $90 \mathrm{~m}$ resolution DEM was obtained from USGS. The digital maps of soil $\mathrm{PH}$, total $\mathrm{N}$, total $\mathrm{K}$ and soil organic matter were derived from the Ministry of Agriculture of China. The average annual temperature and rainfall were provided by China Meteorological Administration. The vector data of faults was provided by the Data Sharing Center of Land Resource Science of Chinese Academy of Sciences. In this paper, these basic data such as administrative boundaries, government headquarters, roads and rivers were downloaded from National Geomatics Center of China.

\subsection{Data process}

The process of $1 \mathrm{~km}$ gridded PRHL data is shown as Fig. 2, specifically including four steps. The step one consists of developing $1 \times 1 \mathrm{~km}$ raster data for rural housing land and verifying the $1 \mathrm{~km}$ gridded demographic data. The former refers to first extracting the rural housing land polygons from the interpreted 


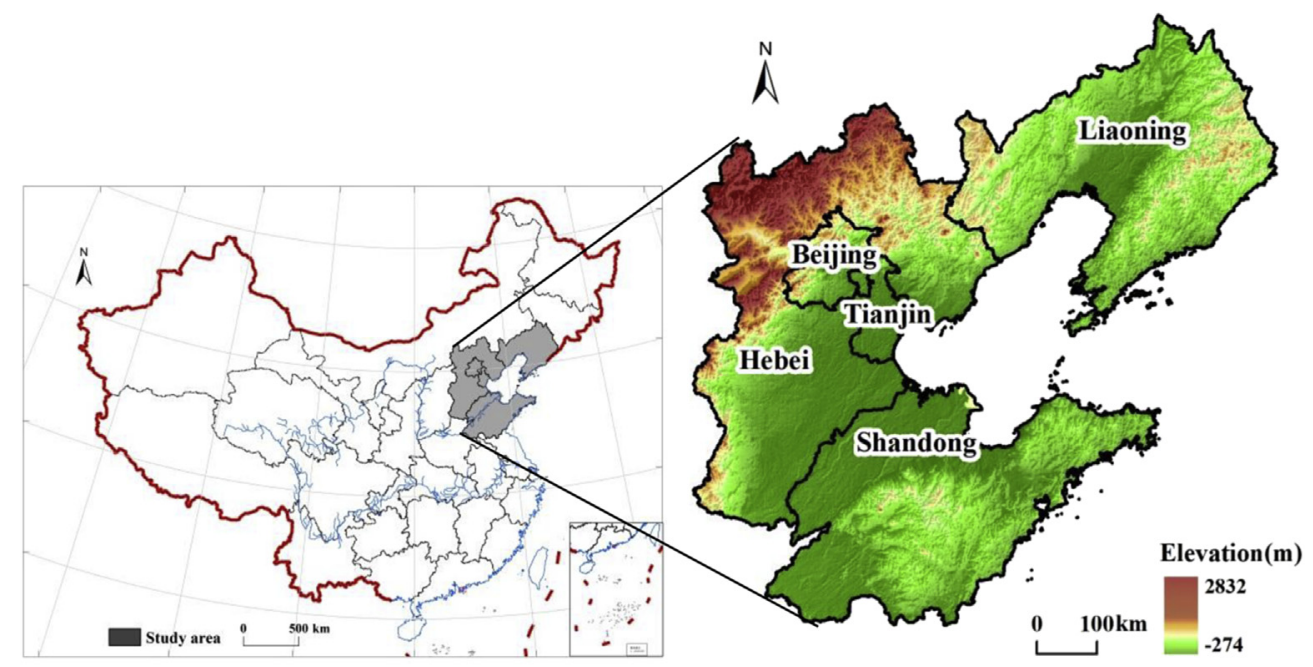

Fig. 1. Location of the study area, Bohai Rim.

remote sensing data, then intersecting and dissolving them with $1 \mathrm{~km}$ gridded fishnet, and finally converting them to raster data, i.e., the $1 \times 1 \mathrm{~km}$ raster data of rural housing land. The latter aims to check the consistency of the population census data at county level with the $1 \mathrm{~km}$ gridded demographic data. If they are equal at county level, the population of each grid in the county will be kept; otherwise, the $1 \mathrm{~km}$ gridded demographic data in corresponding county will be adjusted in proportion. Step two is to use Georeferencing tools in ArcGIS software to adjust $1 \times 1 \mathrm{~km}$ raster data of population and rural housing land obtained from step one so that they will match. After that, we got the $1 \times 1 \mathrm{~km}$ raster data of population in 2000 and 2010, respectively, which had been

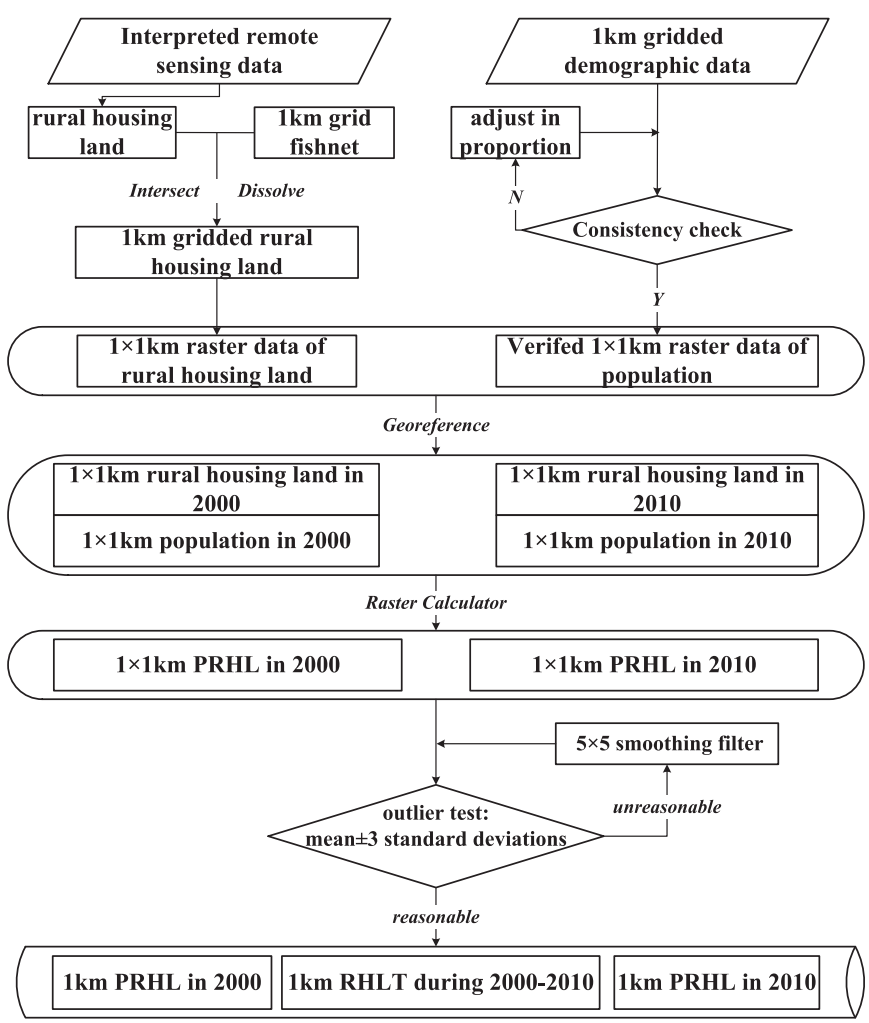

Fig. 2. The process of obtaining $1 \mathrm{~km}$ gridded PRHL data. calibrated. Step three is to get the $1 \mathrm{~km}$ gridded PRHL data. With the help of the "Raster calculator" tool in ArcGIS software, the each grid's PRHL was obtained through divided the rural housing land area by population, then we got the $1 \times 1 \mathrm{~km}$ PRHL in 2000 and 2010 , respectively. Step four is also known as correction of outlier. If the value of one grid is within 3 standard deviations of the mean, it will be considered reasonable. Otherwise, it will be smoothed using $5 \times 5$ smoothing filter until the value is in the reasonable range. At the end, we got the tested $1 \mathrm{~km}$ gridded PRHL in 2000 and 2010, respectively, and the dynamic data of $1 \mathrm{~km}$ gridded PRHL during 2000-2010.

Multi-scale gridded spatial econometric regression analysis (SERA) aims at studying the causality between various independent variables (physical conditions, transportation, and location) and the RHLT at five different scales, i.e., $2 \mathrm{~km}, 3 \mathrm{~km}, 4 \mathrm{~km}, 5 \mathrm{~km}$ and $6 \mathrm{~km}$. The reasons for such design are as follows (Paquette \& Domon, 2003). First, the SERA is limited by the data process capacity of GeoDa software (Anselin, 2003). As shown in Table 1, the number of grids at $1 \mathrm{~km}$ scale is 521,882 , over the upper limit of GeoDa software. However, the number of grids at other scales is within the range. Thus, the method of scale up is taken to solve the problem of GeoDa's limited data processing capacity. Secondly, the multi-scale SERA can successfully avoid the contingency of result caused by the single-scale SERA. So, the results obtained by the multi-scale SERA are more convincing.

The data processing of multi-scale SERA contains the processes of independent variables and dependent variables. The dependent variables refer to RHLT in the aspect of PRHL during 2000-2010 at $2 \mathrm{~km}-6 \mathrm{~km}$ grid scales. The independent variables refer to seven categories consist of 17 indicators (Table 2 and Fig. 3), which in turn are terrain, soil, climate, geology, hydrology, transportation and location. The data processing of the multi-scale variables is as follows:

(1) The terrain can be characterized by elevation and slope. The slope and elevation data were generated from the $90 \mathrm{~m}$ DEM through ArcGIS10.1 ${ }^{\circledR}$ Spatial Analysis toolbox and Resample toolbox with $1 \mathrm{~km}$ resolution.

Table 1

The number of grids at different scales in Bohai Rim.

\begin{tabular}{lllllll}
\hline Scale & $1 \mathrm{~km}$ & $2 \mathrm{~km}$ & $3 \mathrm{~km}$ & $4 \mathrm{~km}$ & $5 \mathrm{~km}$ & $6 \mathrm{~km}$ \\
\hline Number of grids & 521,882 & 131,630 & 59,095 & 33,577 & 21,710 & 15,200 \\
\hline
\end{tabular}


Table 2

The indicator system used in SERA at gridded scale.

\begin{tabular}{|c|c|c|c|}
\hline Variable category & Variable & Description & Unit \\
\hline Dependent variable & RHLT & Rural housing land transition & $\mathrm{m}^{2}$ \\
\hline \multirow[t]{2}{*}{ Terrain } & Elevation & Average elevation & $\mathrm{m}$ \\
\hline & Slope & Average slope & - \\
\hline \multirow[t]{4}{*}{ Soil } & Soil PH & Average Soil PH & - \\
\hline & Total N & Average Total N & $\mathrm{g} / \mathrm{kg}$ \\
\hline & Total K & Average Total $\mathrm{K}$ & $\mathrm{g} / \mathrm{kg}$ \\
\hline & Organic matter & Average organic matter & $\mathrm{g} / \mathrm{kg}$ \\
\hline \multirow[t]{2}{*}{ Climate } & Rainfall & Average annual rainfall & $\mathrm{mm}$ \\
\hline & Temperature & Average annual temperature & $\mathrm{K}$ \\
\hline Geology & Dis2F & Shortest distance to faults & - \\
\hline Hydrology & Dis2R & Shortest distance to rivers & - \\
\hline \multirow[t]{3}{*}{ Transportation } & Dis2HR & Shortest distance to highway/railroads & - \\
\hline & Dis2NP & Shortest distance to national/provincial roads & - \\
\hline & Dis2CV & Shortest distance to county/village roads & - \\
\hline \multirow[t]{4}{*}{ Location } & Dis2PC & Distance to the nearest provincial capital government site & - \\
\hline & Dis2P & Distance to the nearest prefecture government site & - \\
\hline & Dis2C & Distance to the nearest county government site & - \\
\hline & Dis2T & Distance to the nearest township government site & - \\
\hline
\end{tabular}

(2) In China, the rural housing land generally expands in the peripheral area of a village, and it is inevitable to occupy the highquality arable land (Long et al., 2012). Therefore, the RHLT may be related to the soil quality. Considering the data availability, we selected the soil PH, total N, total $\mathrm{K}$ and soil organic matter as the indicators of soil condition, which were derived by the respective maps using vectorization tool and Polygon to Raster tool with $1 \mathrm{~km}$ resolution.

(3) Usually, the climate is characterized by average annual temperature and rainfall, which were integrated on the basis of average data from 1970 to 2000 through kriging interpolation with $1 \mathrm{~km}$ resolution.

(4) The data process of the geological conditions, hydrological conditions, transportation and location were similar. The hydrological conditions and geological conditions were respectively defined as the shortest distance to rivers and faults with corresponding abbreviated name of Dis2R and Dis2F. The transportation was defined as the shortest distance to highway/railroads, national/ provincial roads and county/village roads with the abbreviated names of Dis2HR, Dis2NP and Dis2CV, respectively. The location was presented by the distance to nearest provincial capital government site, the nearest prefecture government site, the nearest county government site and the nearest township government site with the abbreviated names of Dis2PC, Dis2P, Dis2C and Dis2T, respectively. All the distances were calculated by the Euclidean Distance tool with $1 \mathrm{~km}$ resolution.

(5) The final step, also called data scaling up, was mainly to convert above data and the RHLT from $1 \mathrm{~km}$ resolution to $2-6 \mathrm{~km}$ resolution using the Raster-to-Point tools and Analysis tools provided by $\operatorname{ArcGIS}^{\circledR}$. The latter was to respectively intersect the
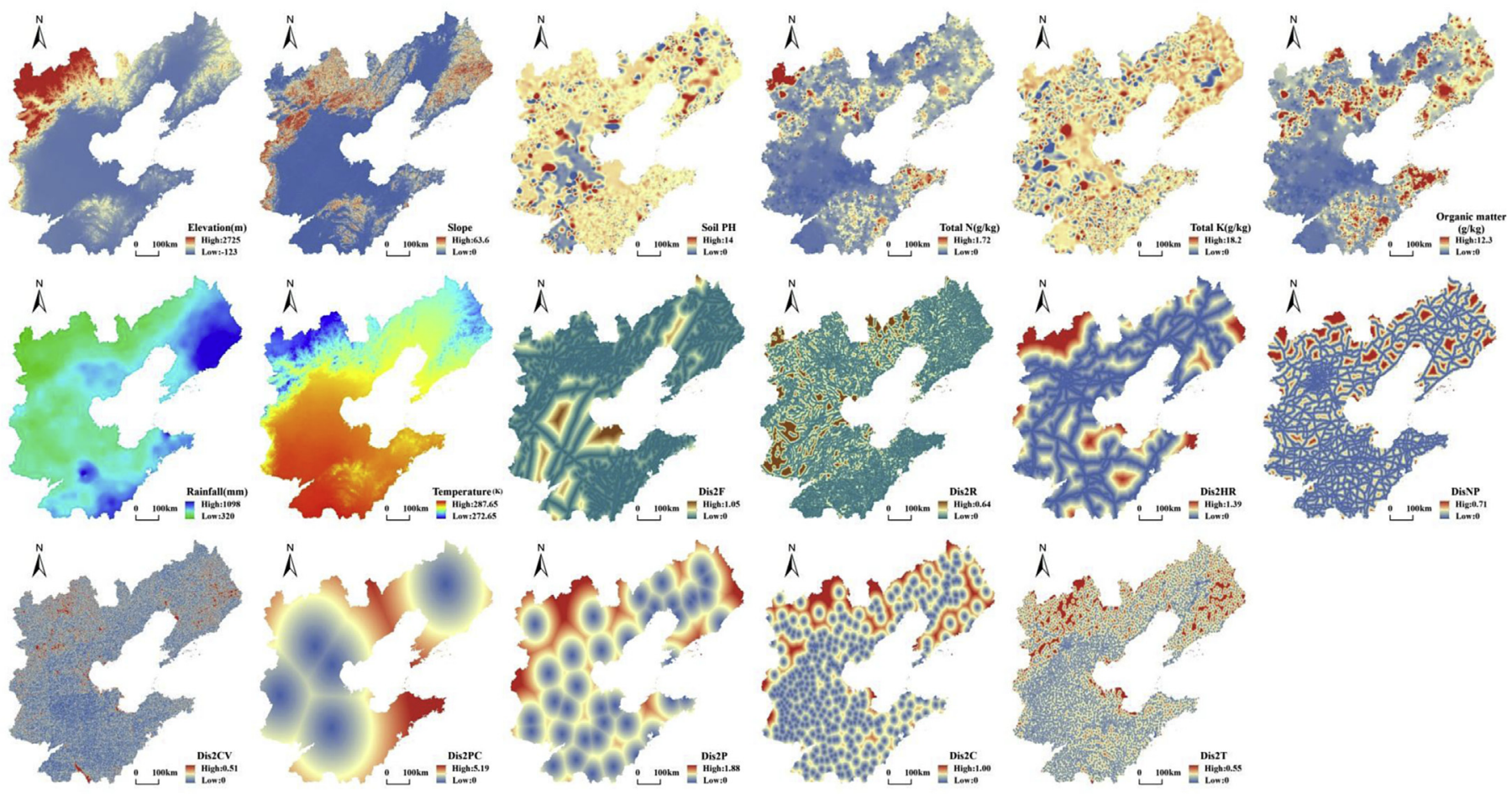

Fig. $3.1 \times 1 \mathrm{~km}$ raster variables. 
$1 \times 1 \mathrm{~km}$ data with the 2-6 km gridded fishnet. Ultimately, five sets of data with $2-6 \mathrm{~km}$ resolution with the gap of $1 \mathrm{~km}$ were generated. These data are used in the SERA analysis.

\subsection{Methodology}

The calculation of $1 \mathrm{~km}$ gridded PRHL is given as:

PRHL $=\frac{\text { RHArea }}{\text { PopSize }} \times 100 \%$

where PRHL is the area of per capita rural housing land in each grid $\left(\mathrm{m}^{2} /\right.$ person), RHArea is the area of rural housing land in each grid $\left(\mathrm{m}^{2}\right)$, PopSize is the population size in each grid (persons).

The hot spot analysis calculates the Getis-Ord $\mathrm{Gi}^{*}$ statistic for each feature in a dataset to demonstrate where features with either high (hot spots) or low (cold spots) values cluster spatially. In this study, the method was used to detect the hot spots (or cold spots) of changes of rural housing land, population and PRHL during 2000-2010. The Getis-Ord $\mathrm{Gi}^{*}$ is given as:

$$
G_{i}^{*}=\sum_{i} W_{i j} Y_{j} / \sum_{j} Y_{j} \text { and } Z\left(G_{i}^{*}\right)=\left(G_{i}^{*}-E\left(G_{i}^{*}\right)\right) / \sqrt{\operatorname{VAR}\left(G_{i}^{*}\right)}
$$

Where $G_{i}^{*}$ is a local spatial autocorrelation index, $Z\left(G_{i}^{*}\right)$ is a test score, $E\left(G_{i}^{*}\right)$ and $\operatorname{VAR}\left(G_{i}^{*}\right)$ are the expected value and the variance of $G_{i}^{*}, W_{i j}$ is spatial weight matrix, $Y_{j}$ is the observed value of $\mathrm{j}$ grid. For statistically significant positive (negative) $Z$ scores, the larger (smaller) the $\mathrm{Z}$ scores, the more intense the clustering high (low) values (Ma, Li, \& Shen, 2012).

It is very important to take spatial dependence into account when dealing with spatial data. In this study, the spatial econometric regression models include Spatial Lag Model (SLM) and Spatial Error Model (SEM). SLM assumes that the value of RHLT depends on the values of it in neighboring regions. It is thus a formulation of the idea of a spatial spillover. An SLM is expressed as follows (Anselin, 1988):

$y=\rho W y+X \beta+\varepsilon$

where $y$ is RHLT in each grid, $X$ contains a set of explanatory variables for the regression relationship with $\beta$ as the corresponding regression coefficient, $\rho$ is a spatial autoregressive coefficient indicating the extent to which variations in the observations $y$ are explained by the average of neighboring observations values, $\varepsilon$ is the model error terms, $W$ is a Queen contiguity spatial weights matrix, which defines a location's neighbors as those with either a shared border or vertex.

Compared with SLM, the spatial dependence in the SEM enters through the errors rather than through the neighboring values of the dependent variable in the SLM (Anselin, 2002; Anselin, Bera, Florax, \& Yoon, 1996). SEM is specified as

$y=X \beta+\varepsilon$ and $\varepsilon=\lambda W \varepsilon+\mu$

where $y, X, \beta, W$ are the same as them in Equation (3), $\lambda$ is a spatial autoregressive coefficient, $\varepsilon$ is regression residuals, $\mu$ is normally distributed random error.

Ordinary least squares (OLS) models the relationship between a dependent variable and a collection of independent variables. The value of dependent variable is defined as a linear combination of the independent variables plus an error term: $y_{i}=\beta_{0}+\sum_{j=1}^{k} \beta_{j} x_{i j}+\varepsilon_{i}$

where $y_{i}$ are the dependent variables, $x_{i j}$ are the independent variables, $\beta_{0}$ is constant term, $\beta_{j}$ are the regression coefficients, $\varepsilon_{i}$ is a normally distributed errors of prediction.

\section{Results}

\subsection{Spatio-temporal pattern of RHLT}

According to the analysis results, the area of rural housing land in Bohai Rim was 3.30 million ha in 2000 and 3.33 million ha in 2010. It expanded 0.03 million ha from 2000 to 2010. The spatiotemporal pattern of rural housing land change was showed as follows.

To some extent, the distribution of the rural housing land was characterized by vertical zonality, i.e., the proportion of rural housing land decreased gradually with the increase of elevation for areas beyond the sea level (elevation $>0 \mathrm{~m}$ ) (Table 3). The plain area (elevation within the range of $0-100 \mathrm{~m}$ ) was the best location choice for rural housing land, and almost 79.0\% rural housing land distributed there, such as Liaohe Plain, Liaotung Peninsula, Hebei Plain, Yellow River flood plain and southwestern Shandong. While there was little rural housing land distributed in areas with high elevations, such as western Liaoning highlands, eastern Liaoning hills, Taihang Mountain, Yan Mountain, and Taishan Mountain (Fig. 4).

There was a substantial increase in the proportion of rural housing land within the elevation range of $0-100 \mathrm{~m}$, increased by $0.4 \%$, from $78.6 \%$ in 2000 to $79.0 \%$ in 2010 . However, there was only a slight change of the proportion of rural housing land within other ranges of elevation, especially for the mountainous-hilly area (elevation $\geq 500 \mathrm{~m}$ ). Increased rural housing land and lost rural housing land during 2000-2010 were fancy of plain areas (within the elevation range of $0-100 \mathrm{~m}$ ), the proportion of which amounted to $66.8 \%$ and $65.0 \%$, respectively, since the intensity of human activities is high in plain areas (Table 3 ).

Rural housing land was more sensitive to slope than to elevation and there was a phenomenon of agglomeration. More than $90 \%$ of the rural housing land concentrated in slight slope areas (slope $<5^{\circ}$ ) and the proportion of rural housing land there increased by $1.1 \%$, from $93.4 \%$ in 2000 to $94.5 \%$ in 2010 (Table 4). On the contrary, the rural housing land in other ranges of slope accounted for a limited proportion, and with a trend of decrease or remaining unchanged. Overall, the proportion of rural housing land decreased obviously with the increase of slope. This was reasonable because the steep site conditions could easily trigger geological disasters which might destroy rural housing land and do great harm to farmers' lives, property and safety. Increased rural housing land and lost rural housing land during 2000-2010 majorly focused on the slight slope area, the proportion of which amounted to $91.2 \%$ and $93.0 \%$, respectively.

The PRHL was generally high in Bohai Rim and the regional differences were significant. The average PRHL increased from $226 \mathrm{~m}^{2}$ to $258 \mathrm{~m}^{2}$ during $2000-2010$, which was far beyond $150 \mathrm{~m}^{2}$ the national highest standard of rural housing land use. This showed a great potential for rural housing land consolidation. Compared with that in 2000, the standard deviations of PRHL in 2010 doubled to $229 \mathrm{~m}^{2}$ within a decade, which indicated that the regional differences of PRHL distribution in Bohai Rim were more obvious. As shown in Fig. 5, the hot spots of RHLT mainly distributed in Liaohe Plain, Beijing suburbs and the border region of Hebei and Shandong. While the cold spots concentrated in eastern 
Table 3

Elevation and rural housing land (RHL) distribution in Bohai Rim (\%).

\begin{tabular}{|c|c|c|c|c|c|c|c|c|c|c|}
\hline Elevation (m) & $\leq 0$ & $0-100$ & $100-200$ & $200-300$ & $300-400$ & $400-500$ & $500-600$ & $600-700$ & $700-800$ & $\geq 800$ \\
\hline Total land area & 3.3 & 47.3 & 11.7 & 7.2 & 5.2 & 4.2 & 3.6 & 2.8 & 2.1 & 12.6 \\
\hline RHL in 2000 & 1.7 & 78.6 & 10.4 & 3.4 & 1.5 & 0.9 & 0.8 & 0.5 & 0.3 & 1.9 \\
\hline RHL in 2010 & 1.5 & 79.0 & 10.5 & 3.1 & 1.3 & 0.9 & 0.9 & 0.5 & 0.3 & 2.0 \\
\hline Increased RHL during 2000-2010 & 1.6 & 66.8 & 13.4 & 5.3 & 2.7 & 1.9 & 1.7 & 1.1 & 0.7 & 4.8 \\
\hline Lost RHL during 2000-2010 & 1.7 & 65.0 & 14 & 6.4 & 3.4 & 2 & 1.5 & 1.1 & 0.7 & 4.2 \\
\hline
\end{tabular}

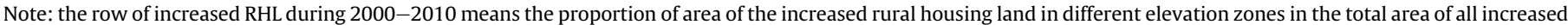
rural housing land; the same as the row of lost RHL during 2000-2010.
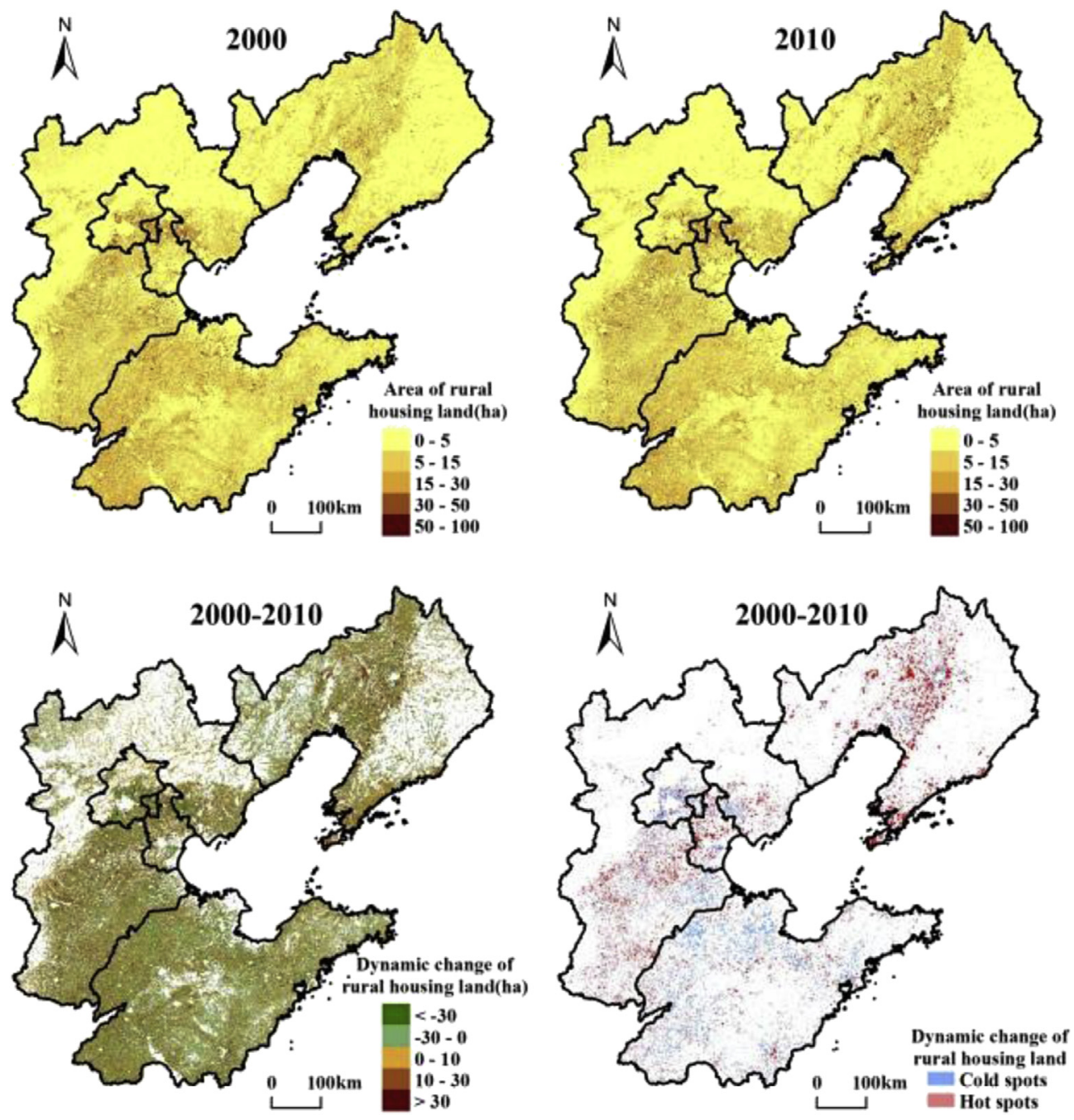

Fig. 4. The spatio-temporal pattern of RHLT in the aspect of rural housing land area during 2000-2010.

Table 4

Slope and rural housing land (RHL) distribution in Bohai Rim (\%).

\begin{tabular}{|c|c|c|c|c|c|}
\hline Slope & Total land area & RHL in 2000 & RHL in 2010 & Increased RHL during 2000-2010 & Lost RHL during 2000-2010 \\
\hline$<5^{\circ}$ & 67.0 & 93.4 & 94.5 & 91.2 & 93.0 \\
\hline $5^{\circ} \sim 8^{\circ}$ & 7.8 & 2.9 & 2.7 & 3.6 & 3.3 \\
\hline $8^{\circ} \sim 15^{\circ}$ & 14.2 & 2.7 & 2.2 & 3.7 & 2.8 \\
\hline $15^{\circ} \sim 25^{\circ}$ & 9.2 & 0.9 & 0.6 & 1.4 & 0.9 \\
\hline $25^{\circ} \sim 35^{\circ}$ & 1.7 & 0.1 & 0.1 & 0.1 & 0.1 \\
\hline$>35^{\circ}$ & 0.1 & 0.0 & 0.0 & 0.0 & 0.0 \\
\hline
\end{tabular}

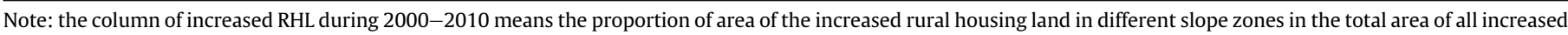
rural housing land; the same as the column of lost RHL during 2000-2010. 
Liaoning hills, Taihang Mountain, Yan Mountain, and Taishan Mountain.

During 2000-2010, the proportion of grids with decreasing and increasing PRHL accounted for $54 \%$ and $46 \%$, respectively. There was regional disparity in the pattern of hot spots: concentrated in a zone in Liaotung Peninsula, scattered across the Liaohe plain, distributed along a line in Taihang Mountain frontier in southern Hebei, and again scattered across Shandong. The cold spots concentrated in Liaohe plain, suburbs of Beijing and Tianjin, northwestern Hebei and the border region of Hebei and Shandong (Fig. 5).

Usually, the RHLT was influenced by both rural housing land change and rural population migration. The result of hot spots analysis showed the spatial mismatch of rural housing land change and rural population migration, which can be summarized as two models. For the first model, the rural population decrease was accompanied by the increase of rural housing land. With the ruralto-urban migration, decreased rural population and improved rural income levels was helpful for the rural people to improve their living conditions, which resulted in the expansion of rural housing land. This RHLT model is primarily concentrated in the three plains in Bohai Rim. Conversely, the second model represented some suburban areas of rapidly developed big cities with increasing rural population and decreasing rural housing land, such as Beijing, Tianjin, Shenyang, and so on. On the one hand, the big cities attracted a lot of migrants gathering to the suburban areas; on the other hand, the expansion of urban areas swallowed up the rural housing land around the cities. Besides these two models, some areas presented the synchronous increase or decrease of rural housing land and rural population. The former mainly located around Baoding where the PRHL decreased because the rural housing land expanded at a slower pace than that of rural population. While the latter mainly located in Shandong except for its northern part where there was a widespread increase of PRHL.

\subsection{Driving forces and mechanism of RHLT}

The dynamic pattern of RHLT is the result of the interaction of physical conditions and socio-economic factors. The physical conditions have a long-term influence on the RHLT, while the socioeconomic factors determine the speed and scale of RHLT in a relatively short period. This study analyzes the physical and socioeconomic driving forces of the RHLT with the aid of spatial econometric regression model at grid scale and county scale, respectively. Based on the above analysis, the driving mechanism of RHLT is further discussed.

\subsection{Driving forces analysis of RHLT at grid scale}

The raster-based explanatory model is one of the approaches to analyze the relationship between independent variables and dependent variable. Based on the SERA, the multi-scale gridded explanatory model was constructed to explore the quantitative relationship between physical conditions and RHLT and reveal the direction and strength of driving forces acting on the RHLT (Deng, Lin, Zhan, \& He, 2009). This paper selects terrain, soil, geology, climate, hydrology, transportation and location to analyze the driving forces.

First, the spatial correlation test based on multi-grid scales of the OLS, SLM and SEM was carried out to determine which model will be more desirable. Table 5 showed that no matter at which scale, the Lagrange Multiplier (error) is more significant than the Lagrange Multiplier (lag) especially for the high level grid scale. Furthermore, the Robust Lagrange Multiplier (error) is more significant than the Robust Lagrange Multiplier (lag). Based on above analysis, we think that the SEM is more suitable for the driving forces analysis of RHLT at grid scale (Table 6). Compared with the multi-scale regression analysis results of $2-6 \mathrm{~km}$ grid, it was found that except for the result of $3 \mathrm{~km}$ grid, the spatial econometric regression analyses of other scales were effective. The increasing $\mathrm{R}^{2}$ with scale up illustrated the validation of interpretation enhanced when the scale went up from $1 \mathrm{~km}$ to $6 \mathrm{~km}$. The significant positive Lambda pointed out that the RHLT in one grid was not only influenced by the socio-economic conditions and physical conditions itself, but also influenced by the RHLT, socio-economic conditions and the physical conditions of neighboring grids.

In addition to Dis2HR, Dis2NP and rainfall, all other factors had significant effects on RHLT. According to the size of regression coefficients, the descending order of factors is Dis2CV, Dis2T, Dis2R, Dis2C, total N, Dis2F, Dis2P, organic matter, Dis2PC, slope, total K, temperature, PRHL in 2000, soil PH, and elevation. Generally speaking, transportation and location have a great effect on RHLT.

(1) Transportation. There were differences between influences of various levels of transportation conditions on RHLT. As the high level transportation, such as railways, highway, the national roads and provincial roads, are relatively enclosed and they have little effects on rural housing land expansion and rural population migration. While the county/village roads led to RHLT through affecting the siting of rural housing. The new rural housing was built along the roads and eventually formed a phenomenon called "along-roads residence".

(2) Location. Dis2C had a significant positive relationship with RHLT which means that the higher the Dis2C, the faster increase in PRHL. The growth of PRHL was increasing along the transect "urban-suburbs-exurbs-rural"; Dis2T had a negative correlation with RHLT, so the grids near the township government site would have dramatic RHLT. The villages around towns generally have higher level of socio-economic development, and the sources of farmer's income are various. So the ability of improving their living condition is strong. In this case, the rural housing land expanded rapidly which resulted in the increase of PRHL dramatically; Dis2PC and Dis2P mainly through absorbing surplus rural labors to affect the spatial distribution of rural population, which led to the RHLT.

(3) Hydrological conditions. Since water is indispensable for the survival of mankind, the siting of the settlements must ensure the access of enough water. The negative correlation between hydrological conditions and RHLT meant the closer to river, the faster growth of PRHL. The regions near rivers are easy to access water for farming and living, so there are a large number of settlements and high quality arable land along the river. In the context of cultivated land abandoned, the farmland becomes preferred site for the expansion of rural housing.

(4) PRHL in 2000. There was significant negative correlation between PRHL in 2000 and RHLT during 2000-2010. The larger the PRHL 2000 was, the slower the RHLT, and vice versa. The rural housing supply in some areas with low PRHL in 2000 cannot meet the rising demand generated by the population growth and improving living conditions. So, the rural housing land will expand and the PRHL grows rapidly.

(5) Environmental conditions. Other conditions, such as geological conditions, terrain, climate and soil, almost have little effects on the RHLT. On the one hand, in a short period, little changes occurred to these conditions and they will have little influences on the changes of rural housing land and the demographic change, which is closely related to socioeconomic development. On the other hand, with the 

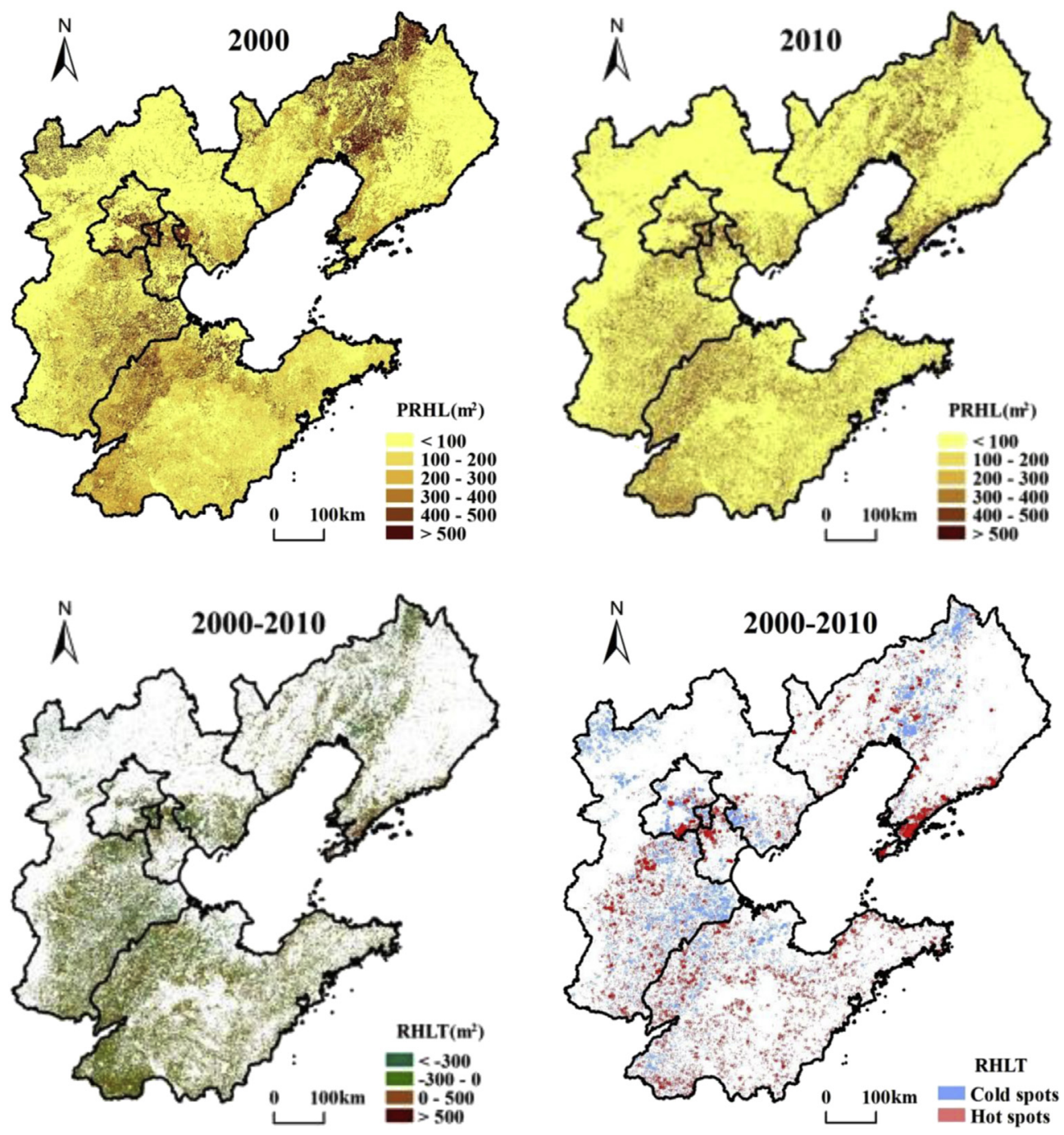

Fig. 5. The spatio-temporal pattern of RHLT in the aspect of PRHL during 2000-2010.

enhancement of building technology, the physical conditions are already not considered as an important factor for the siting of rural housing. However, the lost rural housing occurred in the areas with steep slope, extreme high or low elevation, or poor geological conditions.

\subsection{Driving forces analysis of RHLT at county scale}

In China, county is the smallest unit to obtain the overall socioeconomic data. The results based on county scale analysis can provide a theoretical basis for policy-making. Same methods were selected to determine which SERA model will be suitable for the driving forces analysis of RHLT at county scale. Lagrange Multiplier (lag) (22.08) is more significant than Lagrange Multiplier (error) (19.42). The Robust LM (lag) is significant while the Robust LM (error) is not significant. So we chose SLM for the driving forces analysis of RHLT at county scale (Table 7). The county scale SERA showed that the per capita net income of farmer (PCNI) and rural nonagricultural employment rate (RNER) had significant impacts on RHLT, while the GDP per capita, urbanization and industrialization were not significant as expected. As we expected, the coefficient of PCNI in 2000 was positive (Table 7), which demonstrated the increase of PRHL was directly proportional to PCNI. The high PCNI enhanced the farmers' ability of improving the living conditions. Thus, the overcrowding degree was relieved and the PRHL inevitably increased significantly. Reflecting the degree of nonagricultural employment in rural areas, RNER's coefficient was significantly negative as shown in Table 7. In

Table 5

Results of spatial correlation test based on multi-grid scales.

\begin{tabular}{|c|c|c|c|c|c|}
\hline Test & $2 \mathrm{~km}$ & $3 \mathrm{~km}$ & $4 \mathrm{~km}$ & $5 \mathrm{~km}$ & $6 \mathrm{~km}$ \\
\hline Lagrange Multiplier (lag) & $733.07^{* * *}$ & 0.00 & $199.99^{* * *}$ & $119.94^{* * *}$ & $82.96^{* * *}$ \\
\hline Robust LM (lag) & $314.06^{* * *}$ & $88.07^{* * *}$ & $169.11^{* * *}$ & $158.95^{* * *}$ & $161.536^{* * *}$ \\
\hline Lagrange Multiplier (error) & $2805.40^{* * *}$ & $44.74^{* * *}$ & $1209.22^{* * *}$ & $983.00^{* * *}$ & $898.12^{* * *}$ \\
\hline Robust LM (error) & $2386.40^{* * *}$ & $132.80^{* * *}$ & $1178.34^{* * *}$ & $1022.01^{* * *}$ & $976.69^{* * *}$ \\
\hline
\end{tabular}

*Significance at $10 \% .{ }^{* *}$ Significance at $5 \% .{ }^{* * *}$ Significance at $1 \%$. 
Table 6

Results of SEM at multi-grid scales.

\begin{tabular}{|c|c|c|c|c|c|}
\hline Variable & $2 \mathrm{~km}$ & $3 \mathrm{~km}$ & $4 \mathrm{~km}$ & $5 \mathrm{~km}$ & $6 \mathrm{~km}$ \\
\hline Constant & $536.35^{* * *}$ & $340.49^{* * *}$ & $494.67^{* * *}$ & $478.20^{* * *}$ & $481.55^{* * *}$ \\
\hline PRHL 2000 & $-1.01^{* * *}$ & $-1.05^{* * *}$ & $-0.97^{* * *}$ & $-0.98^{* * *}$ & $-0.97^{* * *}$ \\
\hline Dis2HR & -1.67 & $52.39^{* * *}$ & 10.07 & -0.89 & -13.48 \\
\hline Dis2NP & -3.75 & 43.13 & -30.13 & 7.69 & 0.57 \\
\hline Dis2CV & $-2292.97^{* * *}$ & $-2666.28^{* * *}$ & $-1671.60^{* * *}$ & $-1532.54^{* * *}$ & $-1501.28^{* * *}$ \\
\hline Elevation & $-0.19^{* * *}$ & $-0.21^{* * *}$ & $-0.19^{* * *}$ & $-0.17^{* * *}$ & $-0.17^{* * *}$ \\
\hline Slope & $-4.92^{* * *}$ & $-1.44^{* *}$ & $-3.71^{* * *}$ & $-5.00^{* * *}$ & $-4.19^{* * *}$ \\
\hline Soil PH & $-0.87^{* * *}$ & $-0.88^{* * *}$ & $-0.73^{* *}$ & $-0.55^{* *}$ & $-0.83^{* *}$ \\
\hline Total N & $59.20^{* * *}$ & -69.86 & $61.96^{* * *}$ & $45.63^{* * *}$ & $65.78^{* * *}$ \\
\hline Total K & $3.46^{* * *}$ & -0.43 & $2.62^{* * *}$ & 1.46 & $2.64^{* *}$ \\
\hline Organic matter & $-6.89^{* * *}$ & -0.60 & $-6.78^{* * *}$ & $-6.28^{* * *}$ & $-7.38^{* * *}$ \\
\hline Rainfall & 0.00 & $-0.01^{* * *}$ & 0.00 & 0.00 & 0.00 \\
\hline Temperature & $-1.87^{* * *}$ & -0.12 & $-1.63^{* * *}$ & $-1.52^{* * *}$ & $-1.41^{* * *}$ \\
\hline Dis2R & $-117.83^{* * *}$ & $-128.61^{* * *}$ & -38.02 & -91.13 & $-101.23^{* *}$ \\
\hline Dis2PC & $-6.09^{* * *}$ & $-2.45^{*}$ & $-3.09^{*}$ & -1.39 & -3.27 \\
\hline Dis2P & $15.87^{* * *}$ & $-9.23^{*}$ & 6.79 & $13.78^{* *}$ & 4.86 \\
\hline Dis2C & $78.03^{* * *}$ & $50.98^{* * *}$ & $68.89^{* * *}$ & $55.43^{* * *}$ & $49.15^{* * *}$ \\
\hline Dis2T & -60.31 & $148.42^{* * *}$ & $-222.11^{* * *}$ & $-136.57^{* *}$ & $-186.68^{* * *}$ \\
\hline Dis2F & $25.73^{* * *}$ & -1.83 & $24.05^{*}$ & $36.47^{* *}$ & $28.76^{*}$ \\
\hline Lambda & $0.27^{* * *}$ & $0.05^{* * *}$ & $0.30^{* * *}$ & $0.33^{* * *}$ & $0.33^{* * *}$ \\
\hline $\mathrm{R}^{2}$ & 0.589873 & 0.4894 & 0.640141 & 0.684296 & 0.706594 \\
\hline
\end{tabular}

${ }^{*}$ Significance at $10 \% .{ }^{* *}$ Significance at $5 \% .{ }^{* * *}$ Significance at $1 \%$.

fact, RNER and RHLT might be related in a positive way or a negative way. On the one hand, the increase of RNER made the sources of farmer's income diversity and stimulated the desire of improving living conditions, which led to the increase of PRHL. On the other hand, with the increase of RNER, lots of farmers migrated to cities to seek for jobs, which prevented the expansion of rural housing land and led to the decrease of PRHL. The ultimate relationship between RHLT and RNER is the result of combined action of the above two cases. However, in Bohai Rim, the relationship between them is negative. The factors of urbanization and industrialization are not significant, which was not consistent with previous estimate. As to urbanization, the reason is most likely caused by the typical type of statistical unrealistically high urbanization (Liu \& Yang, 2012). As to industrialization, may be there is no direct but indirect causality between it and RHLT. The GDP per capita is not significant at all. GDP per capita is a comprehensive indicator measuring socio-economic development in both urban and rural systems but not only rural system, so there is no direct causality between it and RHLT.

\subsection{Mechanism analysis of RHLT}

The analysis of driving forces of RHLT at grid scale and county scales shows that the dynamic pattern of RHLT is the result of

Table 7

Results of SLM at county scale.

\begin{tabular}{lc}
\hline Variable & SLM \\
\hline Constant & $5.414^{* *}$ \\
GDP per capita 2000 & 0.001 \\
PCNI 2000 & $0.002^{* *}$ \\
Industralization 2000 & 0.081 \\
Urbanization 2000 & 0.050 \\
RNER 2000 & $-0.176^{* *}$ \\
GDP per capita 2010 & 0.000 \\
PCNI 2010 & 0.000 \\
Industralization 2010 & -0.193 \\
Urbanization 2010 & 0.188 \\
RNER 2010 & -0.061 \\
W-RHLT & $0.336^{* * *}$ \\
$\mathrm{R}^{2}$ & 0.144 \\
\hline
\end{tabular}

* Significance at $10 \% .{ }^{* *}$ Significance at $5 \% .{ }^{* * *}$ Significance at $1 \%$. interaction among various factors, including physical conditions, socio-economic conditions, transportation, location and the PRHL in 2000. These factors finally led to the RHLT, via affecting the rural population migration and rural housing land change. As shown in Fig. 6, solid arrow lines (dotted arrow lines) represent each factor has significant (no significant) effect on RHLT, and the "+" ("-") represents the two variables linked by the arrow line have positive (negative) correlation. The rural housing land change and rural population migration have positive and negative effects on RHLT, respectively.

With the development of science and technology, physical conditions in the aspects of geology, terrain, climate, soil and hydrological factors, have little impact on RHLT. The socio-economic factors, however, have significant and complex effects on RHLT. PCNI and RNER are the key factors driving the RHLT, while the industrialization and urbanization have indirect effects on it through changing farmers' income and employment structure. More remarkably, the transportation and location conditions play an important role in driving RHLT and their interactions with RHLT vary in strength and direction depending on the level of transportation and location. The study found that Dis2CV, Dis2C and Dis2T have great influences on RHLT, which demonstrated the development and construction of towns (including chengguan town that county government site locates in) should be paid more attentions in establishing future urban-town system of China. In addition, the RHLT also was affected by PRHL in base period to a certain extent. The less the PRHL of 2000 is, the more dramatically the RHLT during 2000-2010, and vice versa. Therefore, the implementation of rural housing land consolidation needs to take into account both the status quo and its changing trend of PRHL.

\section{Conclusions and discussion}

This paper uses grid technology with the advantage of precise location to analyze the RHLT in Bohai Rim, the results of which may provide the parameters for potential evaluation of and practical advices for rural housing land consolidation. Gridded research of RHLT perfectly meets the needs of village-town construction and planning under the background of rapid urbanization.

The results of this paper indicated that the distribution of rural housing land was characterized by vertical zonality, i.e., the 


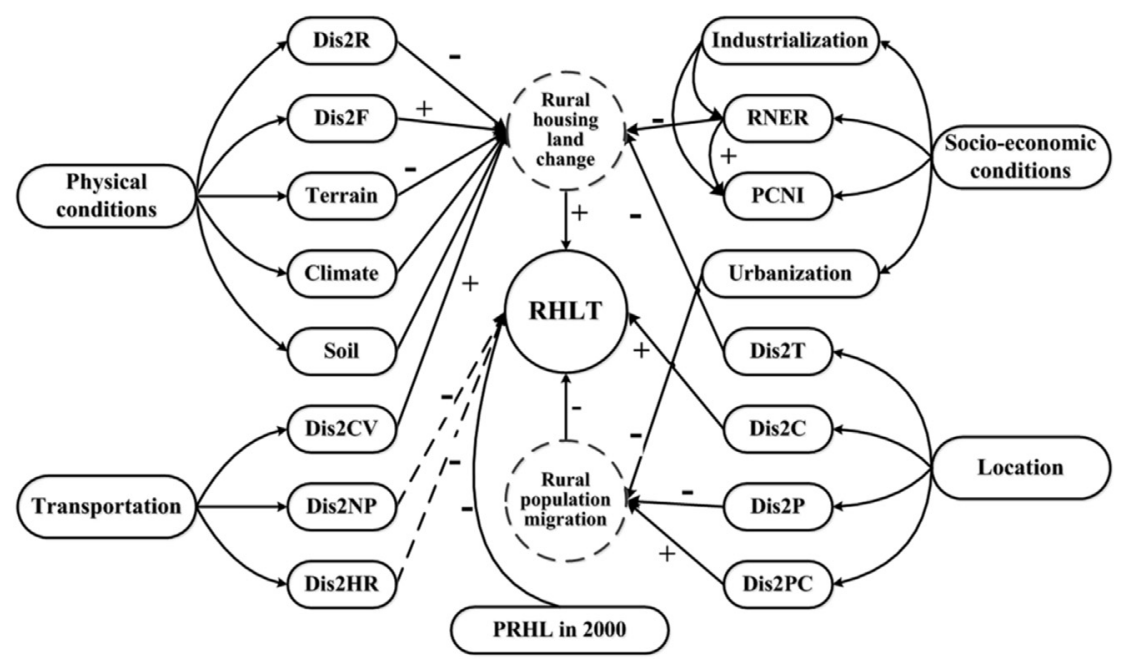

Fig. 6. Driving mechanism of RHLT.

proportion of rural housing land decreased gradually with the increase of elevation, and was more sensitive to slope than to elevation. The plain areas with the elevation range of $0-200 \mathrm{~m}$ and the areas with slight slope $\left(<5^{\circ}\right)$ were the best location choice for the rural housing. The PRHL is generally high in Bohai Rim which was far beyond the national highest standard of rural construction land use, which shows there is a great potential for carrying out rural housing land consolidation.

The results of hot spots analysis showed that the spatial mismatch of rural housing land change and rural population migration made the regional differences of RHLT more remarkable. The rural housing land consolidation should adopt the corresponding reconstruction models and chronological sequence according to the regional differences (Chen et al., 2010; Liu, Liu, \& Zhai, 2009). Generally speaking, there are four regional types of rural housing land consolidation followed by "rural population increase vs. rural housing land decrease", "rural population decrease vs. rural housing land increase", "synchronous decrease of rural housing land and rural population" and "synchronous increase of rural housing land and rural population".

The type of "rural population increase vs. rural housing land decrease" mainly distributed in the suburb of Beijing and Tianjin with the overcrowding and haphazard situation. There is no more land use potential for excavating, so the goal of rural housing land consolidation is not to tap the land use potential but to allocate the infrastructures and public service facilities according to "Beijing city overall plan" and "Tianjin city overall plan", which should include the suburban areas so as to improve the local living environment and achieve the urban-rural integration development.

The type of "rural population decrease vs. rural housing land increase" mainly distributed in Liaotung Peninsula coastal areas and Taihang Mountain frontier in southern Hebei where there are great potential for rural housing land consolidation. The evolution of local hollowed villages has entered the maturity period, which urgently needs to carry out rural housing land consolidation (Liu et al., 2009). The reconstruction or consolidation models to be chosen needs to take into account the village location and the distance to the surrounding villages and towns (Chen et al., 2010). For example, the villages located in the fringe areas of city or surrounding the central town, the "urbanization leading model" may be suitable to solve the space matching problem of employment and living for non-agricultural farmers and to avoid the simultaneously occupation of urban and rural land resources. For the dense villages, the "central village merging model" may be used, which focuses on integrating the scattered villages in the aspect of space, constructing the central village or community and favoring the effective layout of rural public facilities and services facilities. The core of this model is to promote centralized rural living and intensified land use level. Finally, the "intra-village intensifying model" is suitable for scattered villages with extensively utilized land and poor rural infrastructures. The core of this reconstruction model is to strengthen the intensive land use, improve the rural environment and rationally allocate the public resources.

The type of "synchronous decrease of rural housing land and rural population" concentrated in Shandong province except for its northern part. As an important labor-exporting eastern coastal province, the proportion of rural migrant workers in the total rural labors of Shandong was higher than that of other provinces. Meanwhile, Shandong is one of the provinces carrying out rural land consolidation earliest. Therefore, both of rural population and rural housing land decreased during 2000-2010. However, the RHLT in Shandong province was strengthened just because the decrease rate of rural population was faster than that of rural housing land, which indicated that rural housing land consolidation should be continuously carried out according to the above mentioned three reconstruction models.

The type of "synchronous increase of rural housing land and rural population" mainly distributed in Liaohe plain. It indicated that the decline phenomenon of rural areas had not emerged yet and the vacancy rate of the rural housing land was still not high enough to make the potential feasibility for carrying out rural housing land consolidation. In other words, from the perspective of chronological sequence, local rural housing land consolidation needs to be put off a certain period. The local governments may predict the maturity period of rural land consolidation and rural reconstruction in advance and take effective measures to deal with the upcoming extensive land use in rural areas.

During the process of multi-scale SERA, the validation of interpretation enhanced gradually when the scale went up from $2 \mathrm{~km}$ to $6 \mathrm{~km}$. The study found that the RHLT was influenced majorly by socio-economic conditions, especially PCNI and RNER, rather than physical conditions. Besides that, the transportation and location conditions played an essential role in RHLT, especially for the factors of Dis2CV, Dis2C and Dis2T. Therefore, the town would become an important scale to solve rural issues, especially rural land use issues. 
As to PRHL, with the introduction of series of laws and regulations about "one homestead one house", the sprawl of rural housing land has been controlled in the study area, so the RHLT will be mainly affected by rural population migration. The towns have the advantage of low barriers to entry, particularly for the relatively low living costs and social costs, so they will be the main carriers for workers moving from rural areas to cities, which was mentioned in National New-type Urbanization Plan (2014-2020) (Wang, Hui, Choguill, \& Jia, 2015). That will change the recent phenomenon of rural population flowing to big cities to some extent. At present, the population of many towns is decreasing, which demonstrates there is enough space and capacity to carry the migration from rural to urban.

Towns are effective hubs for linking the urban system and rural system. In the process of pushing forward China's new-type urbanization, it is better to get the farmers to migrate to towns instead of big cities. For this, it is necessary to further improve the urban and rural household registration system, to integrate the urban and rural social safeguard system, and to reform the urban and rural land institution. Specifically, there are urgent needs to establish the withdrawing mechanism of rural housing land, the compensation mechanism of rural housing land use, and the multiple guarantee mechanism for farmers whose rural housing land is expropriated. Only by this way can the relationship between outmigrated farmers and rural housing land be orderly and completely removed, so as to smoothly pushing forward rural housing land consolidation.

\section{Acknowledgments}

This work was supported by the National Natural Science Foundation of China (Grant Nos. 41171149 and 41130748) and the National Key Technology R\&D Program of China (Grant No. 2014BAL01B05).

\section{References}

Anselin, L. (1988). Spatial econometrics: Methods and models. Dordrecht: Kluwer Academic Publisher.

Anselin, L. (2002). Under the hood: issues in the specification and interpretation of spatial regression analysis. Agricultural Economics, 27, 247-267.

Anselin, L. (2003). GeoDaTM 0.9 user's guide. Urbana, 51, 61801.

Anselin, L., Bera, A., Florax, R., \& Yoon, M. (1996). Simple diagnostic tests for spatial dependence. Regional Science and Urban Economics, 26, 77-104.

Carmona, A., \& Nahuelhual, L. (2012). Combining land transitions and trajectories in assessing forest cover change. Applied Geography, 32(2), 904-915.

Chan, K. W. (2010). Fundamentals of China's urbanization and policy. China Review, 10, 63-93.

Chen, Y. F., Sun, H., \& Liu, Y. S. (2010). Reconstruction models of hollowed villages in key agricultural regions of China. Acta Geographica Sinica, 65(6), 727-735 (in Chinese).

Chen, R. S., Ye, C., Cai, Y. L., Xing, X. S., \& Chen, Q. (2014). The impact of rural outmigration on land use transition in China: past, present and trend. Land Use Policy, 40, 101-110.

Deng, X. Z., Lin, Y. Z., Zhan, J. Y., \& He, S. J. (2009). Robust estimation of the rasterbased explanatory model for land use pattern. Progress in Geography, 28(6), 912-918 (in Chinese).

Deng, J. S., Wang, K., Hong, Y., \& Qi, J. G. (2009). Spatio-temporal dynamics and evolution of land use change and landscape pattern in response to rapid urbanization. Landscape and Urban Planning, 92, 187-198.

Fang, Y. G., \& Liu, J. S. (2014). The modification of North China quadrangles in response to rural social and economic changes in agricultural villages: 1970-2010s. Land Use Policy, 39, 266-280.

Ferreira, M. P. Alves, D. S. \& Shimabukuro, Y. E. (2015). Forest dynamics and landuse transitions in the Brazilian Atlantic Forest: the case of sugarcane expansion. Regional Environmental Change, 15(2), 365-377.

Gong, J. Z., Chen, W. L., Liu, Y. S., \& Wang, J. Y. (2014). The intensity change of urban development land: Implications for the city master plan of Guangzhou, China. Land Use Policy, 40, 91-100.

Goodman, D. S. G. (2008). China's regional development, fifthed. London: Roya Institute of International Affairs.

Guo, L. Y., Wang, D. L., Qiu, J. J., Wang, L. G., \& Liu, Y. (2009). Spatio-temporal patterns of land use change along the Bohai Rim in China during 1985-2005. Journal of Geographical Sciences, 19(5), 568-576.
Lambin, E. F., \& Meyfroidt, P. (2010). Land use transitions: socio-ecological feedback versus socio-economic change. Land Use Policy, 27, 108-118.

Liang, Z., Chen, Y. P., \& Gu, Y. (2002). Rural industrialisation and internal migration in China. Urban Studies, 39, 2175-2187.

Li, Y. R., Liu, Y. S., \& Long, H. L. (2010). Spatio-temporal analysis of population and residential land change in rural China. Journal of Natural Resources, 25(10), 1629-1638 (in Chinese).

Li, Y. R., Liu, Y. S., Long, H. L., \& Cui, W. G. (2014). Community-based rural residential land consolidation and allocation can help to revitalize hollowed villages in traditional agricultural areas of China: evidence from Dancheng County, Henan Province. Land Use Policy, 39, 188-198.

Lin, Y. L., \& De Meulder, B. (2012). A conceptual framework for the strategic urban project approach for the sustainable redevelopment of "villages in the city" in Guangzhou. Habitat International, 36(3), 380-387.

Liu, Y. S., Fang, F., \& Li, Y. H. (2014). Key issues of land use in China and implications for policy making. Land Use Policy, 40, 6-12.

Liu, Y. T., He, S. J., Wu, F. L., \& Webster, C. (2010). Urban villages under China's rapid urbanization: unregulated assets and transitional neighbourhoods. Habitat International, 34(2), 135-144.

Liu, Y. S., Liu, Y., Chen, Y. F., \& Long, H. L. (2010). The process and driving forces of rural hollowing in China under rapid urbanization. Journal of Geographical Sciences, 20(6), 876-888.

Liu, Y., Liu, Y. S., \& Guo, L. Y. (2011). Zoning and consolidation strategy for rural residential land in the areas around Bohai gulf in China. Transactions of The Chinese Society of Agricultural Engineering, 27(6), 306-312 (in Chinese).

Liu, Y. L., Liu, Z. Q., Kong, X. S., Li, J. W., \& Tan, R. H. (2015). A comparative analysis of urban and rural construction land use change and driving forces: implications for urban-rural coordination development in Wuhan, Central China. Habitat International, 47, 113-125.

Liu, Y. S., Liu, Y. \& Zhai, R. X. (2009). Geographical research and optimizing practice of rural hollowing in China. Acta Geographica Sinica, 64(10), 1193-1202 (in Chinese).

Liu, Y., van Oort, F., Geertman, S., \& Lin, Y. L. (2014). Institutional determinants of brownfield formation in Chinese cities and urban villages. Habitat International, $44,72-78$.

Liu, Y. S., \& Yang, R. (2012). The spatial characteristics and formation mechanism of the county urbanization in China. Acta Geographica Sinica, 67(8), 1011-1020 (in Chinese).

Li, X. B., \& Zhao, Y. L. (2011). Forest transition, agricultural land marginalization and ecological restoration. China Population, Resources and Environment, 21(10), 91-95 (in Chinese).

Long, H. L. (2003). Land use transition: a new integrated approach of land use/cover change study. Geography and Geo-information Science, 19(1), 87-90 (in Chinese).

Long, H. L. (2014a). Land use policy in China: introduction. Land Use Policy, 40, 1-5.

Long, H. L. (2014b). Land consolidation: an indispensable way of spatial restructuring in rural China. Journal of Geographical Sciences, 24(2), 211-225.

Long, H. L., Heilig, G. K., Li, X. B., \& Zhang, M. (2007). Socio-economic development and land-use change: analysis of rural housing land transition in the transect of the Yangtse River, China. Land Use Policy, 24(1), 141-153.

Long, H. L., \& Li, X. B. (2002). Analysis of regional land use transition: a case study in the transect of the Yangtse River. Journal of Natural Resources, 17(2), 144-149 (in Chinese).

Long, H. L., \& Li, T. T. (2012). The coupling characteristics and mechanism of farmland and rural housing land transition. Journal of Geographical Sciences, 22(3), 548-562.

Long, H. L., Li, Y. R., Liu, Y. S., Woods, M., \& Zou, J. (2012). Accelerated restructuring in rural China fueled by 'increasing vs. decreasing balance' land-use policy for dealing with hollowed villages. Land Use Policy, 29, 11-22.

Long, D. P., Li, T. S., Miao, Y. Y., Liu, C., Li, X. Y., \& Meng, H. H. (2014). Spatio-temporal characteristics and impacting factors of non-agriculturalization of China's rural population. Progress in Geography, 33(4), 517-530 (in Chinese).

Long, H. L., Liu, Y. Q., Hou, X. G., Li, T. T., \& Li, Y. R. (2014). Effects of land use transitions due to rapid urbanization on ecosystem services: Implications for urban planning in the new developing area of China. Habitat International, 44, 536-544.

Ma, X. D., Li, Q. L., \& Shen, Y. (2012). Morphological difference and regional types of rural settlements in Jiangsu province. Acta Geographica Sinica, 67(4), 516-525 (in Chinese).

Mather, A. (2004). Forest transition theory and the reforesting of Scotland. Scottish Geographical Journal, 120, 83-98.

Mather, A. (2007). Recent Asian forest transitions in relation to forest transition theory. International Forestry Review, 9, 491-502.

Mather, A., \& Fairbairn, J. (2000). From floods to reforestation: the forest transition in Switzerland. Environment and History, 6, 399-421.

Ministry of Land and Resources of China (MLRC). (2009). Reports on China's land use survey and update in 2008. Beijing: China Land Press.

Mizutani, C. (2012). Construction of an analytical framework for polygon-based land use transition analyses. Computers, Environment and Urban Systems, 36(3), $270-280$.

Mukherjee, A., \& Zhang, X. (2007). Rural industrialization in China and India: role of policies and institurions. World Development, 35, 1621-1634.

National Bureau of Statistics of China (NBSC). (2009). China statistical yearbook. Beijing: China Statistics Press.

Paquette, S., \& Domon, S. (2003). Changing ruralities, changing landscapes: exploring social recomposition using a multi-scale approach. Journal of Rural Studies, 19(4), 425-444. 
Romo-Leon, J. R., van Leeuwen, W. J. D., \& Castellanos-Villegas, A. (2014). Using remote sensing tools to assess land use transitions in unsustainable arid agroecosystems. Journal of Arid Environments, 106, 27-35.

Song, W., \& Liu, M. L. (2014). Assessment of decoupling between rural settlement area and rural population in China. Land Use Policy, 39, 331-341.

Song, Y., Zenou, Y., \& Ding, C. (2008). Let's not throw the baby out with the bath water: the role of urban villages in housing rural migrants in China. Urban Studies, 45, 313-330.

Su, S. L., Jiang, Z. L., Zhang, Q., \& Zhang, Y. (2011). Transformation of agricultural landscapes under rapid urbanization: a threat to sustainability in Hang-Jia-Hu region, China. Applied Geography, 31, 439-449.

Su, S. L., Wang, Y. P., Luo, F. H., Mai, G. C., \& Pu, J. (2014). Peri-urban vegetated landscape pattern changes in relation to socioeconomic development. Ecological Indicators, 46, 477-486.

Su, S. L., Xiao, R., Jiang, Z. L., \& Zhang, Y. (2012). Characterizing landscape pattern and ecosystem service value changes for urbanization impacts at an ecoregional scale. Applied Geography, 34, 295-305.

Su, S. L., Yang, C. X., Hu, Y. N., Luo, F. H., \& Wang, Y. P. (2014). Progressive landscape fragmentation in relation to cash crop cultivation. Applied Geography, 53, $20-31$.
Tan, M. H., \& Li, X. B. (2013). The changing settlements in rural areas under urban pressure in China: patterns, driving forces and policy implications. Landscape and Urban Planning, 120, 170-177.

Tilt, B. (2008). Smallholders and the 'household responsibility system': adapting to institutional change in Chinese agriculture. Human Ecology, 36, 189-199.

Turner, B. L., II, Lambin, E., \& Reenberg, A. (2007). Land change science special feature: the emergence of land change science for global environmental change and sustainability. Proceedings of the National Academy of Sciences of the United States of America, 104, 20666-20671.

Unger, J. (2002). The transformation of rural China. Armonk: ME Sharpe.

Wang, X. R., Hui, E. C. M., Choguill, C., \& Jia, S. H. (2015). The new urbanization policy in China: which way forward? Habitat International, 47, 279-284.

Yang, R., Liu, Y. S., Long, H. L., \& Qiao, L. Y. (2015). Spatio-temporal characteristics of rural settlements and land use in the Bohai Rim of China. Journal of Geographical Sciences, 25(5), 559-572.

Zhang, L. X., Rozelle, S., \& Huang, J. K. (2001). Off-farm jobs and on-farm work in periods of boom and bust in rural China. Journal of Comparative Economics, 29, 505-526.

Zhu, F. K., Zhang, F. R., Li, C., \& Zhu, T. F. (2014). Functional transition of the rural settlement: analysis of land-use differentiation in a transect of Beijing, China. Habitat International, 41, 262-271. 